\title{
Enhancing online distance education in small rural US schools: a hybrid, learner-centred model
}

Claire de la Varre*, Julie Keane and Matthew J. Irvin

University of North Carolina at Chapel Hill, Chapel Hill, NC 27599, USA

(Received 9 February 2010; final version received 30 September 2010)

Online distance education (ODE) has become pervasive and can potentially transform pedagogical practices across primary, secondary and university-based educational systems. ODE is considered a flexible option for non-traditional students such as adult learners and home-schoolers, and a convenient way to deliver remedial courses. ODE is also a feasible and attractive option for rural schools, which educate $29 \%$ of all K-12 students in the United States, and often struggle to provide advanced courses and attract highly qualified teachers. This paper presents qualitative data from both cohorts of a two-year, randomised, controlled research study of online distance learners in US rural high schools. Course providers in $\mathrm{K}-12$ environments often rely on the teacher-facilitator model, which assigns a local staff member in the role of on-site facilitator to operate equipment, distribute instructional materials, and answer questions. In order to address issues of isolation and interaction, and to attend to the local context, our study aimed to develop a learner-centred model of social support at the local, small-school level that emphasises communication and interaction. This expanded role links the local classroom environment more closely with the online environment. The responsibilities for ensuring student success are distributed between online instructor and facilitator: a form of hybrid learning.

Keywords: online distance education; rural; $\mathrm{K}-12$

\section{Introduction}

Online distance education (ODE) is widely acknowledged to have the potential to deliver an individualised, learner-focused educational experience that facilitates the communicative and collaborative skills needed by the twenty-first-century workforce for lifelong and independent learning (Hathaway 2009; Papastergiou 2006; Rumble 2001). The uptake of ODE in US high schools is increasing rapidly and the majority of states now have their own virtual schools (Barbour and Reeves 2009; Hannum and McCombs 2008). ODE is considered a flexible option for non-traditional learners such as adults and home-schooled students, and a convenient way to deliver remedial courses. ODE is also a feasible and attractive option for rural schools, which educate $29 \%$ of all K-12 (primary and secondary) students in the United States, yet often struggle to provide advanced courses and attract highly qualified teachers (Simonson, Schlosser, and Hanson 1999; Simonson et al. 2006).

*Corresponding author. Email: claire_delavarre@unc.edu 
While a large body of research has shown no significant difference in learning outcomes when comparing ODE with traditional face-to-face classes, online students frequently report feelings of isolation and ODE has attrition rates sometimes greater than 50\% (Carr 2000; Parker 1999; Roblyer 2006; Simpson 2004; Zweig 2003). In addition to these concerns, the adoption of computer-based technologies in education has outpaced the ability of researchers to provide empirical and theory-based support for the efficacy of such technologies (Cavanaugh et al. 2004; Garrison, Anderson, and Archer 2001; Slough and Mueller 2006). As a result, theories applied to ODE tend to come either from classroom-based educational research, research into online media in the field of communications, or sociological literature (Hiltz et al. 2000). In addition, the bulk of ODE research has been conducted on samples of post-secondary learners, so evidence to support positive outcomes and thus the use of specific technologies or strategies in ODE is currently minimal or lacking, particularly in $\mathrm{K}-12$ populations (Barbour 2007; Cavanaugh et al. 2004).

This paper presents qualitative data from a two-year, randomised, controlled research study of online distance learners in US rural high schools. Course providers in $\mathrm{K}-12$ environments often rely on the teacher-facilitator model, which assigns a local staff member in the role of on-site facilitator to operate equipment, distribute instructional materials, and answer questions. The standard training for facilitators, often known as mentors, typically includes technical training, and suggestions for helping students keep track of assignments and monitoring progress (Michigan Department of Education 2002). For populations of rural students in small schools, we hypothesised that this level of support was insufficient to address issues of isolation and attend to the local context.

Our study aimed to develop a learner-centred model of social support at the local, small school level that emphasised communication and interaction in addition to the basic duties expected of a facilitator. This expanded teacher-facilitator model offers an enhanced role for the on-site facilitator that includes frequent communication with online instructors, contact with local school staff and parents when necessary, encouraging students to interact with their online peers, and creating a positive classroom climate. Our model allows facilitators to offer support tailored to the unique needs of their particular community of learners, something that is difficult for a remote online instructor who may have over 100 online students spread over multiple course sections. This expanded role links the local classroom environment more closely with the online environment, and the responsibilities for ensuring student success are distributed between online instructor and facilitator. Students are enrolled in a course delivered completely online, yet also meet and interact face-to-face in their local classrooms every day with their facilitator. The course thus becomes a form of hybrid (blended) learning, which is frequently seen as an effective way of harnessing and integrating the best features of Internet-based and face-to-face teaching and learning (Garrison and Kanuka 2004). This expanded teacher-facilitator model is intended to be sustainable in rural environments and replicable to other contexts where ODE is implemented. Given the expanded use of on-site facilitators to support students in online courses, it was necessary to fully understand whether our model more effectively addressed issues of student isolation and dropout compared with the standard facilitator training.

Analysis of quantitative data from the first cohort revealed significant differences between intervention and control groups in terms of student retention, with control group schools dropping out at a much greater rate (44\%) than the intervention group 
schools (11\%) (de la Varre et al. 2009; Hannum et al. 2008). Data from the second cohort were less conclusive, which we hypothesised was due in part to teacher experience, and to smaller initial numbers of students per teacher. The purpose of this paper is therefore to provide a more detailed picture of facilitators' classroom practices that the quantitative findings alone cannot address. Qualitative data, from facilitator interviews and teacher debriefing meetings, was intended to help us understand whether there were differences between intervention and control facilitator practices in the classroom and whether those could be connected to our learnercentred facilitator training model.

\section{Literature review}

The twenty-first century has seen exponential growth in online education in the United States, with almost all public colleges and universities now offering online courses, and over 700,000 K-12 students being served through virtual schools in the 2005/06 school year (Picciano and Seaman 2007; Tucker 2007). As a result, institutions have updated their computing infrastructures and incorporated emerging technologies to accommodate online courses and students. This often necessitates profound changes in administrative, financial, and delivery models, requiring new forms of training for teachers, and different modes of assessment and evaluation (Tucker 2007). The majority of states now have their own virtual high schools (Barbour and Reeves 2009; Hannum and McCombs 2008), many of which can be considered a new kind of institution, a combination of 'entrepreneurship and technology' (Tucker 2007). In a survey of online teachers, $74 \%$ said that their experiences in teaching online changed their teaching practices both online and in traditional classroom settings (Tucker 2007).

Online learning has the potential to be transformative on many levels (Garrison and Kanuka 2004). This includes opening up access to a broader and more diverse range of students than has traditionally attended college campuses, and offering a feasible alternative to rural schools that often struggle to fund and attract highlyqualified teachers and offer advanced courses (Hobbs 2004). There are additional benefits for rural communities. ODE could potentially broaden educational and career opportunities for high school students, and rural schools better prepare their students for post-secondary education where digital literacy is essential. Such students, once professionally qualified, are more likely to return to rural areas to live and work (Collins 1999; Easterbrook et al. 1999). Thus investment in ODE at the high school level ultimately could have transformative effects on rural communities, many of which are currently experiencing population decline. Online learning can be particularly effective at the point where it intersects with face-to-face classroom learning. Hybrid (blended) learning, currently being used by $63 \%$ of US school districts (Allen and Seaman 2006), combines the benefits of asynchronous discussion, such as time for reflection and the ability to edit comments before posting, with the immediacy of classroom-based learning experiences and in-person opportunities for community-building (Garrison and Kanuka 2004). Referring to higher education settings, Garrison and Kanuka (2004) believe that in online and hybrid courses it is vital to assess both the outcomes (e.g. satisfaction, dropout, and academic achievement) and the learning process. It seems appropriate to apply this statement to $\mathrm{K}-12$ environments too.

Student isolation, attributed to a lack of personal interaction and support, and frustration caused by the absence of non-verbal cues, is a significant factor in the high 
dropout rates commonly reported in ODE studies (Carr 2000; Diaz 2002; Moore and Kearsley 1996; Picciano 2002; Roblyer 2006). Students who are geographically separated may feel disconnected and ODE courses are often characterised by a lack of teacher immediacy - a psychological closeness between teacher and student (Arbaugh 2001; Rourke et al. 1999). The 'distance' in ODE can be problematic for any student, but is particularly so for rural students (Hobbs 2004). Rural students are accustomed to being educated in learning environments with high levels of intimacy and teacher immediacy, and typically feel a strong sense of belonging and connectedness both to school and community (de la Varre et al. 2009; Hedlund 1993).

In spite of having adequate academic and technological abilities, the adjustment to the demands of ODE may be greater for rural students than for their urban or suburban counterparts (Hannum et al. 2009). Online learners in rural high schools have their own unique needs due to a combination of individual characteristics, the characteristics of their rural community, and local environmental factors (de la Varre et al. 2009). Research in ODE rarely examines the local context in which the learning happens (Dingle et al. 2000) nor does it typically consider that learning, and the social interactions that affect students' experiences of the course, often occur outside the online environment (de la Varre et al. 2009). The presence of a local facilitator, who acts as the 'eyes and ears' of the online instructor, is thought to enhance learning (Hannum and McCombs 2008). Little research has specifically examined the impact of the facilitator role on outcomes; however, Singh and Dika (2003) found that a combination of academic and social support from adults was important for positive outcomes in terms of educational aspirations, academic effort expended, and academic self-concept.

\section{The intervention}

All facilitators in the study were given basic, Web-based training before the start of the course. This included instruction in how to use Blackboard, how to contact the dedicated help desk, how to access grades, how to help their students log in, and tips to give students about online etiquette, good Internet citizenship, and how to avoid plagiarism. Facilitators were to keep the online instructor abreast of student issues and any unexpected local events.

The facilitators in the intervention group were given scenario-based training in applying learner-centred classroom practices to motivate and encourage their students, and develop a supportive classroom climate. This included supporting their students in their online interactions with other remote students and the online instructor as well as in their interactions with peers in the physical environment. These practices were based on the set of 14 learner-centred psychological principles (LCPs) developed by the American Psychological Association (1997), which were intended to guide educational reform at all levels. The evidence on the effectiveness of these learner-centred principles in classrooms has been widely documented (McCombs and Miller 2007). LCPs indicate that learning is social in nature and that social interactions are a key element in learning. LCPs also outline other factors critical for learning, focusing on four research-validated domains: cognitive and metacognitive, motivational and affective, developmental and social, and individual differences. In recently applying this theoretical framework to ODE, McCombs and Vakili (2005) suggest that interpersonal connections foster success in both face-to-face and online learning environments. Creating an environment that supports both the online and offline interaction is seen as a vital contributor to success: "focusing on building collaboration and 
group interaction may be more important than focusing on individual participation" (Simonson et al. 2006, 83).

The intervention training module involved a substantial discussion component in which intervention facilitators interacted with their peers across the country via online discussion forums on a variety of topics. The scenario-based training was intended to foster the development of an online community of facilitators to whom the individuals in the intervention group could turn for advice and support in their facilitator role.

\section{Methods}

The interview data upon which this paper is based come from a study funded by the US Department of Education. In order to compare our expanded model of facilitator support with the standard facilitator training usually provided by online courses, a randomised, controlled, cluster study was designed with two cohorts (2007/08 and 2008/09) comprising over 700 students from 93 rural schools geographically dispersed across the United States. Each school was required to appoint an on-site facilitator to be present when the students took the class each day. See Appendix 1 for full details of the study design.

\section{Data collection}

All facilitators were interviewed by telephone at the end of the academic year. Intervention facilitators were also interviewed at the mid-year point. Part of the mid-year interview involved structured feedback from an online survey administered only to intervention facilitators and their students that enabled comparison of perceptions of facilitators' learner-centred practices in the classroom (see de la Varre et al. 2009; Hannum et al. 2008). Additionally, online instructors were debriefed at the end of each year, when they discussed their perceptions of how well each facilitator had performed in terms of communication and responsiveness. These interviews were conducted in order to understand the relationship between the intervention and actual facilitator practices within the classroom throughout the year.

\section{Data analysis}

We transcribed the facilitator interviews and teacher debriefing meetings, and developed a coding scheme using the most common themes that emerged from the data. Each main theme could be further divided into a number of sub-categories. Interview transcripts were imported into qualitative data analysis software (MAXQDA 2007) and coded, allowing us to further explore these categories and their interrelationships. The themes that emerged from the data were then tied back to the conceptual framework of the study that incorporated LCPs, as well as best practices that have been substantiated by research in distance learning courses over the past decade (Berge 1995). We applied the same coding scheme across both intervention and control facilitators to compare interview responses across these themes. This enabled us not only to compare their overall experiences in the course, but also to gain a better understanding of how facilitator training that incorporated LCPs might affect facilitator practices and student support. To contextualise the comments provided by facilitators during interviews, we also incorporate qualitative findings from the year-end debriefing meetings with the online instructors. 


\section{Results}

Based on our analyses, the main themes that emerged from coding the transcripts of facilitator interviews were: expectations and role definition, strategies used in the classroom, online training, communication, perceptions of student experiences, and long-term benefits for students.

\section{Expectations and role definition}

For the facilitators in the control group, training-related feedback pointed to a lack of clarity about their role and the standard training materials did not seem to offer enough guidance. One facilitator commented: "I wanted more clarification about what the goals were for the course and knowing better what my role as facilitator should be ...what is appropriate, and how and when should I help the students". Facilitators in the control group often made suggestions about what they thought a facilitator should do, such as: "it might have been good to read along with the class, but I didn't want to contaminate the experiment by altering the class environment" or "ideally I would see the facilitator role as being a bit like a teaching assistant in college courses". Unfortunately the perceived lack of clarity over role might have interfered with the control group facilitators' natural instincts in the classroom. One control facilitator described an incident where students had issues with a particular examination: "they were really stumped and when I tried to talk with them I realized that I was crossing the line into teaching and so I backed away from these kinds of conversations entirely". Another, who was an English teacher, was wary of helping with contentrelated questions although this frustrated the students: "I was unsure of what line I was crossing".

Although role ambiguity did not appear to be an issue with the intervention facilitators, there were some comments regarding expectations. At least one intervention facilitator noted that a training scenario helped to clarify the facilitator role for her and that she was planning to adopt some of the strategies modelled: "I saw one or two of my students becoming discouraged when they didn't do better on the quiz. I'm beginning to see my role as cheerleader and encourager".

For some intervention facilitators, particularly those with an English teaching background, "the hardest part of the facilitator role was not being the teacher". One facilitator even wondered "how the other facilitators coped, especially those not from an English background". The online instructors had their own opinions about facilitators who were also English teachers:

You'd think that English teachers would make better facilitators because they can help them with the assignments ... but at the same time if they don't see the merit in the assignment they are going to tell the kids "if I was teaching this assignment then this is how I would do it ..."

\section{Strategies used in the classroom}

Regardless of the fact that the facilitator is a non-teaching role, some facilitators did read the novels along with their students, initiated conversations about the course content, and arranged review sessions that were scheduled outside class time. Although not part of the expanded teacher-facilitator model, this teaching component brings the overall course environment closer to a traditional definition of blended 
learning for those classes where it occurred. However, the model should be easy to implement in rural school settings, so any available and committed staff member with a bachelor's degree should be able to take on the role. It is unrealistic to expect that the facilitator should be a teacher, particularly in rural schools where staff members often perform multiple roles, and when a primary benefit of ODE for rural schools is that it provides access to courses and teachers that otherwise would be unavailable.

All intervention facilitators encouraged students not to take mistakes too seriously and to see them as part of the distance learning process and the majority helped students see the value of learning as its own goal. One intervention facilitator said that she "kept telling the students that they were learning more than they thought", while another "tried to impress upon them that bailing out when things get rough is not an option once you get to college". Most intervention facilitators reported telling students that they consider themselves to be learners too: "I tried to impress upon the kids that this was a partnership, it makes them work harder if they know that". Almost all intervention facilitators made themselves available for students to talk to, and saw their role as supporting and encouraging their students in various ways. Most also met with students to go over online learning problems or assignments they got wrong or led class discussions when students experienced difficulty. In several of the intervention schools, the facilitators were actively engaged in the students' learning process, arranging for students to spend time with the English teacher on staff, and to speak to the school counsellor or even the principal, when necessary.

\section{Online training}

The intervention group facilitators had a lot to say about their scenario-based training and participated in online discussion at 10 times the rate of their control group peers. A number of them liked the scenarios because they raised issues that were mirrored in the classroom during the year. They not only gave intervention facilitators ideas about how they should behave and interact with their students, but about what behaviours to expect from their students: "The scenarios were exactly what my kids were going through - it gave me a good range of ideas to try with my students". Several intervention facilitators referred to the usefulness of specific scenarios in helping them manage situations in their own classrooms, particularly issues around student fears, course rigor, the online format, organisation, time management and peer interactions.

\section{Communication between peers}

One of the scenarios modelled ways to encourage students to interact with their peers, both in the local environment and online. While none of the control facilitators mentioned peer-to-peer communication, a number of intervention facilitators said they actively encouraged their students to talk to peers; for example, "Why don't you come up with solutions then brainstorm with each other?" Some talked about the benefits of peer-to-peer discussion:

I think it is great when my students ask each other for advice. They are learning better how to work with one another and pull ideas together, as well as be willing to listen to other points of view, which will be a good tool when doing any group work, such as the university classroom they will encounter in the future. 
Another intervention facilitator noted that her students were enjoying the new perspectives they gained through interacting with their online peers, and that "this was their favorite part of this course".

\section{Communication between facilitators and instructors}

Overall, facilitators in both the intervention and control groups talked frequently about their relationship with the online instructor. A couple of the intervention group facilitators also mentioned the importance of keeping the online instructor abreast of local situations: "An important part of my role was to act as a go-between - making sure the online instructors were aware of what was happening locally". Online instructors noted that their 'best' facilitators were those with whom they communicated frequently and developed a personal relationship, and those who also encouraged their students to contact the instructor when they needed help: "Most of the people that ended up emailing me on a regular basis ended up being good facilitators. Those that didn't email me at all didn't necessarily do something wrong, they are just not as good". She added: "One would send me pictures every time one of her cows had a calf ...".

\section{Student communication with the online instructor}

Teachers believed that the students were asking fewer questions online than they would have in a face-to-face situation. One facilitator offered a possible explanation for this: "They didn't ask as many questions as they would have in a face-to-face situation because didn't expect a quick response". Although the online instructors responded within a 24-hour period, differences in time zones and local schedules meant that course interactions were almost always asynchronous. Some facilitators encouraged their students to contact the online instructor directly when they needed help or had questions; but for students who needed an answer immediately, the questions would sometimes go unasked. One intervention facilitator negotiated with her school to allow the students to download and install Skype (www.skype.com) to communicate with the teacher. If that had been part of the communication from the start, she felt that the beginning of the year would have been much easier. In particular, it helped to "know the teacher was human":

My kids got a headset with microphone. With a few clicks, they were able to carry on a verbal conversation! The first boy to talk to her said afterwards, "She's nice!" It brings a whole new feeling to the class to actually realize the instructor is a real person, not just some sadistic slave-driving dragon.

\section{Student experiences}

Facilitators in both the control and intervention groups reported overwhelmingly that the main challenges facing students taking the online College Board Advanced Placement Program ${ }^{\circledR}\left(\mathrm{AP}^{\circledR}\right)$ class (http://www.collegeboard.com/student/testing/ap/ about.html) were the rigour of the course and grading, the online format, the lack of face-to-face communication, and the lack of immediate feedback from the online instructor. Many facilitators echoed the following comment:

The students had a difficult time initially with the format. They did not like the lack of immediate feedback from the teacher that they are used to in a face to face class. It took them a while to get used to the online environment. 
Several facilitators noted that their students had no idea before the class started about the volume or rigor of the work: the "AP level was frustrating initially - of course they did not realize how much work it was".

Several facilitators commented on the combination of AP rigour and online format: "with the first unit, the adjustment to the online format had their heads spinning" and "they had never had experience with AP and they were overwhelmed and wanted the social aspect of the traditional face to face course". These were particularly difficult experiences for many students because, in most cases, they were the highestachieving students in their school.

The lack of face-to-face interaction was difficult for many students to overcome, and communication from a distance required different strategies. According to one facilitator: "Students who might speak up in class when they have a question don't always email questions when they think of them as it requires more effort to do so". Several facilitators believed this was particularly true for students in small rural schools, for example:

Students are used to the intimate, small rural setting - have grown up in that place, kindergarten is only one building away from high school and everything is very familiar. It was hard for them to adjust to the online setting and they were frustrated with not being able to ask questions and get an immediate response.

\section{Long-term benefits}

Facilitators in both the intervention and control groups were aware that those students who persisted in the course benefited in a number of ways; however, while all facilitators recognised personal growth in students, only the intervention facilitators mentioned that they actively discussed the longer-term benefits with their students. As one control facilitator noted:

this was a great experience for the child that stuck it out: in terms of organization skills, ability to converse about literature; I have seen amazing growth. This girl is now confident about heading to college, and I wish the other students could have stuck it out too.

At another control school, the facilitator said "For a couple of my kids this class was perfect - they are creative, reflective, inward looking students, and I saw a lot of personal growth over the course of the year in all the students". A third control facilitator stated that this course helped to prepare college-bound students who would be facing a very different learning environment at university: "I really felt that this course prepared these students for the next level - all of them are going on to college, two of them with full scholarships". One intervention facilitator believed that "the course completers show a lot more confidence and think about life more". A number of others commented on personal growth and said they saw students taking increased responsibility for work as the year progressed, "It was hard work, but worth it - they definitely feel more prepared and glad they stuck with it". Several of the intervention facilitators mentioned proactively discussing the current and future benefits of this course with their students:

I keep reminding them what they are getting out of this and what knowledge they will go to college with. Just being involved in this educational process, being exposed to the readings, the discussions, communicating with others ... they are learning a lot. 


\section{Discussion}

Berge (1995) states that, in online learning models, four components typically make up the online instructor role: pedagogical, social, organisational and technical. In our course, using the expanded teacher-facilitator model, these components are distributed between the online instructor and the on-site facilitator. The instructor is responsible for teaching the course and following the curriculum, while the social, organisational and technical components are the joint responsibility of the instructor and the facilitator, who communicate regularly. In this study, the online instructor included opportunities for social interaction within the course, primarily through asynchronous discussion forums, while the facilitator provided local support. The instructor established a timetable and schedule of assignments while the onsite facilitator assisted students in learning time management and self-regulation skills. The instructor covered basic technical skills for the students, while the facilitator was available to help with technical questions in the local classroom. These mutual responsibilities created a truly hybrid learning environment. The extent to which the onsite facilitators took responsibility for the social, organisational and technical areas of the course depended on their own personal characteristics, echoing a similar finding by Kirby and Driscoll (1997). These characteristics included learner-centredness, professional training, assignment to the intervention or control group, their perception of the facilitator role, and the needs and characteristics of their students.

All facilitators reported that students were frustrated and overwhelmed, particularly at the beginning of the course. However, intervention facilitators seemed to have a greater variety of strategies to employ in the situations that occurred over the academic year, and found the scenarios they had encountered during training to be relevant and realistic. This may explain why they felt more comfortable in their role and better able to anticipate students' needs. Conversely, control facilitators were less clear about their role and sometimes expressed nervousness about stepping outside perceived boundaries.

Facilitators in this study were all staff in small rural schools and most knew their students very well. Some who were teachers had also taught these students previously or currently. The emphasis on LCPs in the training encouraged the intervention group to build on these close, pre-existing relationships and to provide students with individualised, timely, local support for online learning. Overall, intervention facilitators held a broad view of the value of online learning and recognised the importance of exposing these students to rigorous coursework. One intervention facilitator summarised the experience of her class:

Attempting difficult challenges will raise awareness of what it takes to achieve goals. Even if you don't get that top grade, you might learn valuable lessons in organization, dedication, and work ethics. This can lead to higher self-esteem and the willingness to persevere through difficult situations again.

\section{Conclusion}

The students and facilitators in this study had access to an online, academicallyadvanced course that would not otherwise have been available. Intervention facilitators learned new strategies to offer learner-centred support to their rural online students as they engaged with rigorous content and interacted with their virtual peers. Online teachers felt that the best facilitators were ones with whom they had a good, 
working relationship, who were consistently responsive in their interactions with the teacher, and engaged with and interested in their students. Facilitators in general saw this course as an important step in preparing students for post-secondary education.

While technology in education has promised transformational change, it has often come up short in its potential to impact large institutions of learning (Cuban 2001; Tyack and Cuban 2004). However, the near-ubiquitous implementation of online learning, particularly as hybrid classes, requires these same institutions to update infrastructure and enable pedagogical shifts to support learners (Tucker 2007). Both of these steps were taken in this study. In their meta-analysis, Cavanaugh et al. (2004) included a caveat: "The temptation may be to attempt to apply or adapt findings from studies of $\mathrm{K}-12$ classroom learning or adult distance learning, but $\mathrm{K}-12$ distance education is fundamentally unique". We would add that rural $\mathrm{K}-12$ distance education is fundamentally unique. Our expanded teacher-facilitator model incorporates the context of the local schools and communities, builds on the traits that often characterise rural school environments, and links the virtual course to the educational setting in which the student is physically embedded. By doing so, our model increases the leverage for ODE to transform education for rural high school students.

\section{Acknowledgements}

This work was supported by a Research and Development Center grant (R305A04056) from the Institute of Education Sciences to the National Research Center on Rural Education Support.

\section{References}

Allen, E., and J. Seaman. 2006. Making the grade: Online education in the United States, 2006. Needham, MA: The Sloan Consortium.

American Psychological Association. 1997. Learner-centered psychological principles: A framework for school reform and redesign. http://www.apa.org/ed/cpse/LCPP.pdf.

Arbaugh, J.B. 2001. How instructor immediacy behaviors affect student satisfaction and learning in web-based courses, Business Communication Quarterly 64, no. 4: 42.

Barbour, M.K. 2007. Principles of effective web-based content for secondary school students: Teacher and developer perspectives. Journal of Distance Education 21, no. 3: 93-114.

Barbour, M.K., and T.C. Reeves. 2009. The reality of virtual schools: A review of the literature. Computers \& Education 52: 402-16.

Berge, Z.L. 1995. Facilitating computer conferencing: Recommendations from the field. Educational Technology 35, no. 1: 22-30.

Carr, S. 2000. As distance education comes of age, the challenge is keeping the students. Chronicle of Higher Education 47, no. 8: A39-41.

Cavanaugh, C., K. Gillian, J. Kromney, M. Hess, and R. Blomeyer. 2004. The effects of distance education on K-12 student outcomes: A meta-analysis. Naperville, IL: Learning Point Associates.

Collins, T. 1999. Attracting and retaining teachers in rural areas. Charleston, WV: ERIC Clearinghouse on Rural Education and Small Schools. (ERIC Document Reproduction Service No. ED 438152).

Cuban, L. 2001. Oversold and underused: Computers in the classroom. Cambridge, MA: Harvard University Press.

de la Varre, C., J. Keane, M.J. Irvin, and W. Hannum. 2009. Social support for online learning. In Handbook of research on socio-technical design and social networking systems, ed. B. Whitworth and A. de Moor, 574-87. Hershey, PA: IGI Global.

Diaz, D.P. 2002. Online drop rates revisited. The Technology Source May/June. http://technologysource.org/article/online_drop_rates_revisited/.

Dingle, J., L. Napp, W. Gooch, and A. Kelly. 2000. Today’s fad or tomorrow's future? http:// horizon.unc.edu/projects/issues/papers/Dingle.html. 
Easterbrook, M., M. Godwin, R. Wilson, G. Hodgetts, G. Brown, R. Pong, and E. Najgebauer. 1999. Rural background and clinical rural rotations during medical training: Effect on practice location. Canadian Medical Association Journal 160: 1159-63.

Garrison, D.R., T. Anderson, and W. Archer. 2001. Critical thinking, cognitive presence and computer conferencing in distance education. The American Journal of Distance Education 15, no. 1: 7-23.

Garrison, D., and H. Kanuka. 2004. Blended learning: Uncovering its transformative potential in higher education. Internet and Higher Education 7: 95-105.

Hannum, W.H., and B.L. McCombs. 2008. Enhancing distance learning for today's youth with learner-centered principles. Educational Technology 48, no. 3: 11-21.

Hannum, W.H., M.J. Irvin, P-W. Lei, and T.W. Farmer. 2008. Effectiveness of using learnercentered principles on student retention in distance education courses in rural schools. Distance Education 29: 211-29.

Hannum, W.H., M.J. Irvin, J.B. Banks, and T.W. Farmer. 2009. Distance education use in rural schools. Journal of Research in Rural Education 24, no. 3: 1-15.

Hathaway, D.M. 2009. Assessing quality dimensions and elements of online learning enacted in a higher education setting. PhD diss., George Mason University.

Hedlund, D. 1993. Listening to rural adolescents: Views on the rural community and the importance of adult interactions. Journal of Research in Rural Education 9, no. 3: $150-9$.

Hiltz, S.R., N. Coppola, N. Rotter, M. Turoff, and R. Benbunan-Fich. 2000. Measuring the importance of collaborative learning for the effectiveness of ALN: A multi-measure, multi-method approach. Journal of Asynchronous Learning Networks 4, no. 2: 103-25.

Hobbs, V. 2004. The promise and the power of online learning in rural education. Arlington, VA: Rural School and Community Trust.

Kirby, E., and M. Driscoll. 1997. Facilitator and student roles and performance in a high school online education course. Paper presented at the annual meeting of the American Education Research Association, March, in Chicago, IL.

MAXQDA. 2007. Software for qualitative data analysis, 1989-2010. VERBI software. Consult. Sozialforschung GmbH, Berlin-Marburg-Amöneburg, Germany.

McCombs, B.L. and L. Miller. 2007. Learner-centered classroom practices and assessments: Maximizing student motivation, learning and achievement. Thousand Oaks, CA: Corwin Press.

McCombs, B. L., and D. Vakili. 2005. A learner-centered framework for e-learning. Teachers College Record 107: 1582-600.

Michigan Department of Education. 2002. Guidance on virtual learning - Educational alternatives. http://www.michigan.gov/documents/virtual02_2002_18549_7.pdf.

Moore, M.G., and G. Kearsley. 1996. Distance education: A systems view. Belmont, CA: Wadsworth.

Papastergiou, M. 2006. Course management systems as tools for the creation of online learning environments: Evaluation from a social constructivist perspective and implications for their design. International Journal on E-Learning 5, no. 4: 593-622.

Parker, A. 1999. A study of variables that predict dropout from distance education. International Journal of Educational Technology 1, no. 2: 1-10.

Picciano, A.G. 2002. Beyond student perceptions: Issues of interaction, presence, and performance in an online course. Journal of Asynchronous Learning Networks 6, no. 1: $21-40$.

Picciano, A.G., and J. Seaman. 2007. K-12 online learning: A survey of US school district administrators. Needham, MA: Alfred P. Sloan Foundation.

Roblyer, M.D. 2006. Virtually successful: Defeating the dropout problem through online school programs. Phi Delta Kappan 88: 31-6.

Rourke, L., Anderson, T., Garrison, D.R., and Archer, W. 1999. Assessing social presence in asynchronous text-based computer conferencing. The Journal of Distance Education 14, no. 2: $50-71$.

Rumble, G. 2001. Re-inventing distance education: 1971-2001. International Journal of Lifelong Education 20, nos 1/2: 31-43.

Simonson, M., C. Schlosser, and D. Hanson. 1999. Theory and online education: A new discussion. American Journal of Distance Education 13: 60-75. 
Simonson, M., S. Smaldino, M. Albright, and S. Zvacek. 2006. Teaching and learning at a distance: Foundations of online education. 3rd ed. Upper Saddle River, NJ: Pearson.

Simpson, O. 2004. The impact on retention of interventions to support distance learning. Open Learning 19, no. 1: 79-96.

Singh, K., and S. Dika. 2003. The educational effects of rural adolescents' social networks. Journal of Research in Rural Education 18, no. 2: 114-28.

Slough, N., and C. Mueller. 2006. Exploring the effects of instructor feedback methods in asynchronous discussion forums. Paper presenetd at the AIB-SE(USA) 2006 Annual Meeting, Clearwater Beach, FL.

Tyack, D., and L. Cuban. 2004. Tinkering toward utopia: A century of public school reform. Excerpts from a conversation at the Askwith education forum, Harvard School of Education, HGSE News. http://www.gse.harvard.edu/news/features/utopia03012004.html.

Tucker, B. 2007. Laboratories of reform: Virtual high schools and innovation in public education. Education Sector Reports June. http://www.educationsector.org.

Zweig, J.M. 2003. Vulnerable youth: Identifying their need for alternative educational settings. Washington DC: Urban Institute. http://www.urban.org/UploadedPDF/410828 _vulnerable_youth.pdf.

\section{Appendix 1. Description of study design}

In each cohort of the Enhancing Rural Online Learning study, students took a year-long online class in Advanced Placement (AP) English Composition and Literature. The AP course was offered through LearnNC, a North Carolina-based organisation that developed the teacherfacilitator model employed in the study. The course was delivered through Blackboard, a commonly-used, off-the-shelf content management system. Schools were required to have a minimum of four students to be eligible for inclusion in the study. Participating schools were randomly assigned to either the intervention group or control group, with the intervention group being exposed to an enhanced learner-centred approach. Once schools were assigned, sections of the online course, with 20-25 students per section, were created to include up to four schools. Each course section formed a discrete, virtual classroom and each of the five online instructors taught several sections. A pre-test modelled on an AP English examination was administered to students before they started the online course. The results from the pre-test showed no differences in the scores or abilities of the students across groups.

Schools within each treatment group were randomly distributed across instructors, with instructors blind to the assignment of schools. To prevent contamination, each section consisted of either all-control students or all-intervention students and peer-to-peer interactions were limited to those peers in the same section. While students were assigned a specific class period each day where they collectively complete that day's assignments, the class was asynchronous because schools within any given section were on different schedules and often in different time zones. The online instructor had to respond to students within a 24-hour period. 